\title{
Prediction of hypotension in spinal anesthesia
}

\author{
Sungsik Park
}

Department of Anesthesiology and Pain Medicine, School of Medicine, Kyungpook National University, Daegu, Korea

According to recent government statistics report [1], people over 65 years of age comprised $11.8 \%$ of the Korean population in the year 2012 and will comprise more than $15 \%$ of the total Korean population before the year 2020. In addition, the percentage of the population aged over 65 years is expected to double to $\sim 32.3 \%$ by the year 2040 compared with the year 2020 . The rate of population aging in Korea is now the highest worldwide [2]. On the other hand, advances in surgical and anesthetic techniques have enabled aged people to more safely undergo surgical operations. Accordingly, elderly patients will become a large proportion of anesthetic practice, and anesthesiologists thus need to be familiar with age-related physiological changes.

Although there is debate surrounding which anesthetic methods are best for elderly patients, most anesthesiologists prefer spinal anesthesia, especially for orthopedic, genitourinary, and gynecological surgeries. However, the limited cardiovascular reservoirs of elderly patients sometimes make anesthesia more complicated than expected.

High-level blockade ( $\geq$ T5) and old age ( $\geq 40$ years) are the two main factors in hypotensive complication after spinal anesthesia, which has an incidence of 15.3 to $33 \%[3,4]$. Therefore, in elderly patients who are scheduled to undergo surgery under spinal anesthesia, prediction of hypotension is important for proper anesthetic management.

In an article published in this issue of Korean Journal of Anesthesiology, Kweon et al. [5] concluded that heart rate variability (HRV) is not a reliable predictor of hypotension after spinal blockade in hypertensive patients. As the authors mentioned in the article, differences in patient samples and anesthetic methods might have resulted in the negative predictive value of HRV, contrary to the findings of other studies [6,7].
Many factors can affect HRV in various ways. Elderly people usually have higher sympathetic activity than younger people. In addition, Abhishekh et al. [8] showed that females have a significantly lower sympathetic tone than that of males in healthy volunteers. Liao et al. [9] showed lower HRV, including the low-frequency (LF) and high-frequency (HF) components, in patients with hypertension, excluding the LF/HF ratio. The lower HRV of patients with hypertension reflects reduced cardiac autonomic control due to various underlying pathophysiological factors. In addition, patients with diabetes mellitus (DM) complicated by cardiovascular autonomic neuropathy may develop abnormalities in heart rate control with central and peripheral vascular dysfunction [10]. When patients have concurrent hypertension and DM, a significant graded decrease in HRV indices may occur. According to these data, it is reasonable that patient age, sex and coexisting diseases should be considered together for patient selection for HRV studies.

As Kweon et al. [5] mentioned, other factors that affect HRV could contribute to negative results. Various antihypertensive medications could change the cardiovascular responses to spinal anesthesia [11]. Physicians prefer antihypertensive drugs that do not increase sympathetic nervous system (SNS) activity or even lower SNS activity. In addition, we must consider the block level. When compared with the study by Hanss et al. [6], the level of spinal blockade in the study by Kweon et al. is too broad (T1T10), and resulted in diverse sympathetic blockade.

In conclusion, although the study by Kweon et al. showed no changes in HRV, we should be aware of various factors that can affect the activity of the autonomic nervous system and be prepared for potential hypotensive events in elderly patients with hypertension scheduled to undergo spinal anesthesia.

Corresponding author: Sungsik Park, M.D., Department of Anesthesiology and Pain Medicine, School of Medicine, Kyungpook National University, 680, Gukchabosang-ro, Jung-gu, Daegu 700-721, Korea. Tel: 82-53-200-3494, Fax: 82-53-426-2760, E-mail: sspark@knu.ac.kr (c) This is an open-access article distributed under the terms of the Creative Commons Attribution Non-Commercial License (http:// creativecommons.org/licenses/by-nc/3.0/), which permits unrestricted non-commercial use, distribution, and reproduction in any medium, provided the original work is properly cited. 


\section{References}

1. Korean National Statistical Office. Population projections for Korea: 2010-2060. Based on the 2010 population and housing census. Daejeon, Korea National Statistical Office. 2011.

2. Kinsella K, He W. National Institute of Health. U.S. Census Bureau, Series P95/09-1. An aging world: 2008 International population reports. Washington, US Government Printing Office. 2009.

3. Carpenter RL, Caplan RA, Brown DL, Stephenson C, Wu R. Incidence and risk factors for side effects of spinal anesthesia. Anesthesiology 1992; 76: 906-16.

4. Tarkkila P, Isola J. A regression model for identifying patients at high risk of hypotension, bradycardia and nausea during spinal anesthesia. Acta Anaesthesiol Scand 1992; 36: 554-8.

5. Kweon TD, Kim SY, Cho SA, Kim JH, Kang YR, Shin YS. Heart rate variability as a predictor of hypotension after spinal anesthesia in hypertensive patients. Korean J Anesthesiol 2013; 65: 317-21.

6. Hanss R, Bein B, Weseloh H, Bauer M, Cavus E, Steinfath M, et al. Heart rate variability predicts severe hypotension after spinal anesthesia. Anesthesiology 2006; 104: 537-45.

7. Hanss R, Renner J, Ilies C, Moikow L, Buell O, Steinfath M, et al. Does heart rate variability predict hypotension and bradycardia after induction of general anaesthesia in high risk cardiovascular patients? Anaesthesia 2008; 63: 129-35.

8. Abhishekh HA, Nisarga P, Kisan R, Meghana A, Chandran S, Trichur Raju, et al. Influence of age and gender on autonomic regulation of heart. J Clin Monit Comput 2013; 27: 259-64.

9. Liao D, Sloan RP, Cascio WE, Folsom AR, Liese AD, Evans GW, et al. Multiple metabolic syndrome is associated with lower heart rate variability. The Atherosclerosis Risk in Communities Study. Diabetes Care 1998; 21: 2116-22.

10. Maser RE, Lenhard MJ. Cardiovascular automatic neuropathy due to diabetes mellitus: clinical manifestations, consequences, and treatment. J Clin Endocrinol Metab 2005; 90: 5896-903.

11. Del Colle S, Morello F, Rabbia F, Milan A, Naso D, Puglisi E, et al. Antihypertensive drugs and the sympathetic nervous system. J Cardiovasc Pharmacol 2007; 50: 487-96. 